\title{
Entrevistas em pesquisas qualitativas
}

\section{Interviews in qualitative research}

\author{
Rosália Duarte*
}

\begin{abstract}
RESUMO
O uso de entrevistas em pesquisas qualitativas é tema recorrente e ainda polêmico nas discussões acadêmicas, pois se trata de um procedimento de coleta de informações que muitas vezes é utilizado de forma menos rigorosa do que seria desejável. Cabe aos pesquisadores que fazem uso de entrevistas em suas investigações explicitar as regras e pressupostos teórico/metodológicos que norteiam seu trabalho, de modo a ampliar o debate acerca da necessária definição de critérios para avaliação de confiabilidade de pesquisas científicas que lançam mão desse recurso. Este texto tem como objetivo contribuir com a realização dessa tarefa. Palavras-chave: entrevista, metodologia de pesquisa, pesquisas qualitativas.
\end{abstract}

\begin{abstract}
The use of interviews in qualitative researches is a matter and still controversial subject in the academic arguments, therefore interviews are a kind of collect informations procedure that many times is employed less rigorously than it would be recommended. Researchers which use interviews in their inquiries should set out the rules and budgets theoretical and methodological that lead their work, to contribut to extend the debate about the necessary definition of criteria for evaluation of the scientific researches reliability in using this kind of resort. This text intents to contribute to the achievement of that task.
\end{abstract}

Key-words: interviews, research methods, qualitative research.

* Psicóloga, doutora em Educação e professora de graduação e Pós-Graduação do Departamento de Educação da PUC-Rio. E-mail: rosalia@edu.puc-rio.br 


\section{Introdução}

Esse é um tema recorrente nas discussões acadêmicas sobre metodologia de pesquisa, e ainda um tanto polêmico. Persistem entre nós certas crenças segundo as quais a entrevista, sobretudo aberta ou semi-estruturada, é um procedimento de coleta de informações pouco confiável e excessivamente subjetivo, pelo qual optam pesquisadores com pequena bagagem teórica, que dele fazem uso de forma bem menos rigorosa do que seria desejável.

É possível que o uso que fizemos das entrevistas em nossas investigações, em algum momento tenha contribuído para que esse tipo de crença se difundisse. Mas é possível, também, que a desconfiança em relação a esse instrumento, privilegiado na coleta de dados em pesquisas de base qualitativa, se deva à ausência, mais ou menos comum em nossos relatórios, teses e dissertações, de um relato minucioso dos procedimentos que adotamos tanto no uso quanto na análise do material recolhido. Penso que a explicitação de regras e pressupostos teórico/metodológicos que norteiam (ou, pelo menos, deveriam nortear) o trabalho com entrevistas pode subsidiar parte das discussões que dizem respeito aos critérios de rigor e confiabilidade a serem adotados na avaliação de pesquisas científicas que lançam mão desse recurso com maior regularidade. Este texto pretende contribuir para a realização dessa tarefa.

\section{Equívocos, obstáculos e possibilidades no uso de entrevistas em pesquisas qualitativas}

É necessário dizer, em primeiro lugar, ainda que pareça redundância, que entrevistas não são a única maneira de se fazer pesquisa qualitativa não existe vínculo obrigatório entre pesquisas qualitativas e a realização de entrevistas. Portanto, não é porque um pesquisador opta pela adoção de um método qualitativo que ele tem, necessariamente, que recorrer a entrevistas (sejam elas de que natureza for). Podemos fazer observações de campo e tomar nossos registros como fonte; podemos recorrer a documentos (escritos, registrados em áudio ou vídeo, pictóricos etc.); podemos fazer fotografias ou videogravações de situações significativas; podemos trabalhar com check lists, grupos focais, questionários, entre outras possibilidades. $\mathrm{O}$ que dá o caráter 
qualitativo não é necessariamente o recurso de que se faz uso, mas o referencial teórico/metodológico eleito para a construção do objeto de pesquisa e para a análise do material coletado no trabalho de campo.

Convém assinalar, também, que entrevistas não são adequadas a todos as situações de pesquisa - há circunstâncias em que elas simplesmente não funcionam ou sequer podem ser realizadas. Quando uma investigação se inscreve, por exemplo, em um contexto em que o anonimato dos interlocutores precisa ser preservado e estes pertencem a uma comunidade onde sua fala e sua história podem facilmente ser reconhecidas pelos demais, deve-se buscar outros meios para levantamento de material empírico. Em presídios, hospitais psiquiátricos ou instituições onde exista violência ou abuso de poder, é evidentemente desaconselhável realizar entrevistas de caráter pessoal.

Se entramos em uma instituição escolar onde se verifica uma crise disputa de poder, perseguição política, denúncias de desvio de verbas, implantação de um projeto polêmico, confronto com traficantes de drogas, violência etc.- provavelmente os profissionais que ali trabalham (assim como os estudantes) não estarão dispostos a arriscar sua segurança pessoal para fornecer informações a um pesquisador, mesmo que reconheçam que os resultados desse trabalho poderiam vir a contribuir para a solução do problema. Cabe ao pesquisador avaliar a situação, antes de sua entrada no campo, para escolher de que recursos vai lançar mão.

Entrevistas são fundamentais quando se precisa/deseja mapear práticas, crenças, valores e sistemas classificatórios de universos sociais específicos, mais ou menos bem delimitados, em que os conflitos e contradições não estejam claramente explicitados. Nesse caso, se forem bem realizadas, elas permitirão ao pesquisador fazer uma espécie de mergulho em profundidade, coletando indícios dos modos como cada um daqueles sujeitos percebe e significa sua realidade e levantando informações consistentes que lhe permitam descrever e compreender a lógica que preside as relações que se estabelecem no interior daquele grupo, o que, em geral, é mais difícil obter com outros instrumentos de coleta de dados.

Muitas vezes a opção pela entrevista baseia-se numa percepção, mais ou menos corrente entre nós, de que esse é um procedimento mais fácil, quando comparado a outros aparentemente mais trabalhosos e mais sofisticados. Cabe assinalar, então, que entrevista é trabalho, não bate-papo informal ou conversa de cozinha. Realizar entrevistas de forma adequada e rigorosa não é mais simples do que lançar mão de qualquer outro recurso destinado a coletar informações no campo: talvez elas tomem menos tempo na fase preparatória do que a elaboração de questionários ou ckeck lists por exemplo, mas para 
serem realizadas de modo a que forneçam material empírico rico e denso o suficiente para ser tomado como fonte de investigação, demandam preparo teórico e competência técnica por parte do pesquisador.

Realizar entrevistas, sobretudo se forem semi-estruturadas, abertas, de histórias de vida etc. não é tarefa banal; propiciar situações de contato, ao mesmo tempo formais e informais, de forma a "provocar" um discurso mais ou menos livre, mas que atenda aos objetivos da pesquisa e que seja significativo no contexto investigado e academicamente relevante é uma tarefa bem mais complexa do que parece à primeira vista.

A realização de uma boa entrevista exige: a) que o pesquisador tenha muito bem definidos os objetivos de sua pesquisa (e introjetados — não é suficiente que eles estejam bem definidos apenas "no papel"); b) que ele conheça, com alguma profundidade, o contexto em que pretende realizar sua investigação (a experiência pessoal, conversas com pessoas que participam daquele universo - egos focais/informantes privilegiados - , leitura de estudos precedentes e uma cuidadosa revisão bibliográfica são requisitos fundamentais para a entrada do pesquisador no campo); c) a introjeção, pelo entrevistador, do roteiro da entrevista (fazer uma entrevista "não-válida" com o roteiro é fundamental para evitar "engasgos" no momento da realização das entrevistas válidas); d) segurança e auto-confiança; e) algum nível de informalidade, sem jamais perder de vista os objetivos que levaram a buscar aquele sujeito específico como fonte de material empírico para sua investigação.

O planejamento (e "ensaio" prévio) da atuação nas situações de contato, a escolha de uma roupa neutra (traje formal, sem mensagens escritas ou iconográficas que possam sugerir pontos de vista pessoais ou envolvimentos com movimentos religiosos, políticos, étnicos etc.) e a pontualidade também ajudam a garantir a qualidade do material a ser recolhido em entrevistas semi-estruturadas.

Analisar entrevistas também é tarefa complicada e exige muito cuidado com a interpretação, a construção de categorias e, principalmente, com uma tendência bastante comum entre pesquisadores de debruçar-se sobre o material empírico procurando "extrair" dali elementos que confirmem suas hipóteses de trabalho e/ou os pressupostos de suas teorias de referência. Precisamos estar muito atentos à interferência de nossa subjetividade, ter consciência dela e assumi-la como parte do processo de investigação. Como diz Geraldo ROMANELLI (1998):

“A subjetividade, elemento constitutivo da alteridade presente na relação entre sujeitos, não pode ser expulsa, nem evitada, mas deve ser admitida e explicitada e, assim, controlada pelos recursos teóricos e metodológicos 
do pesquisador, vale dizer, da experiência que ele, lentamente, vai adquirindo no trabalho de campo". (p.128)

Respostas em aberto e plenas de significados, que por sua vez difíceis de serem apreendidos e fixados "objetivamente", prestam-se, facilmente, a interpretações excessivamente subjetivas (superinterpretações, diria Umberto ECO, 1993) e à "ilustração" de teorias consolidadas. É fundamental, portanto, que programas de Pós-Graduação destinados a formar pesquisadores ensinem a fazer e a analisar entrevistas e que mantenham seus pesquisadores mais experientes, acompanhando esse aprendizado de perto.

Se as entrevistas forem realizadas em grande número, o que é sempre desejável, é bom que a análise não seja feita de forma artesanal (recorte e colagem simples de fragmentos, por exemplo). Pesquisadores seniors analisam entrevistas semi-estruturadas de modo artesanal porque já o fizeram inúmeras vezes ao longo de suas vidas e construíram maneiras próprias de fazêlo, aprendendo a distanciar-se o suficiente para não fazer uso instrumental do conteúdo delas (se fazem esse tipo de uso não é por inexperiência). Entretanto, quando se trata de pesquisadores em formação, o risco de haver uma leitura equivocada do material é maior. Aqui, o uso de softwares para análise de dados qualitativos se justifica e, em alguns casos, se impõe. Existem excelentes programas de computador que ajudam a dar um tratamento mais organizado e mais rigoroso ao grande volume de material empírico contido em entrevistas semi-estruturadas, diários de campo, grupos focais, videogravações etc. '; uma vez adquiridos e registrados pela Instituição, esses programas podem ser disponibilizados a todos os seus membros (professores, pesquisadores, estudantes de graduação e Pós-Graduação, técnicos das equipes de pesquisa e assim por diante) e atualizados regularmente.

Um "mito" muito comum relacionado ao uso de entrevistas na pesquisa de campo é o de que elas servem para legitimar a fala de interlocutores com pouco poder social ou para "dar voz" a comunidades silenciadas, oprimidas, vítimas de arbitrariedades etc. Essa é uma idéia enganosa: por mais engajado, politizado e sensível aos problemas sociais que um pesquisador seja, ele é o idealizador e o condutor de um trabalho científico, construído a partir de regras e pressupostos definidos à revelia do contexto social que ele analisa. Mesmo estando integrado à comunidade, seu papel ali não é igual ao de seus

${ }^{1}$ O NUD*IST e o ATLAS estão entre os softwares mais eficientes e amigáveis para a realização desse tipo de trabalho. 
informantes; ele planeja e dirige o que será produzido ao longo da investigação - a não ser que tenha como norma conceder à comunidade em estudo amplo acesso à definição dos procedimentos de pesquisa, à discussão de todos os trabalhos e compartilhe com ela a autoria do relatório, dissertação, tese, artigo, livro etc., o que é muitíssimo incomum e, na maior parte das vezes, pouco recomendável ${ }^{2}$. Fora desses parâmetros, é a fala do pesquisador que será ouvida no relatório de pesquisa e não a da comunidade silenciada; uma fala polifônica, espera-se, pois a ela estarão incorporadas as vozes dos informantes, mas, ainda assim, uma fala pessoal, de natureza acadêmico/científica, emitida a partir de um lugar de poder.

Assumir que somos autores de nossas pesquisas, assim como do texto produzido a partir dela, não significa, de modo algum, desqualificar nossos informantes, minimizar a importância do olhar deles em relação ao contexto estudado ou arrogar-nos o lugar de sujeito-suposto-saber; significa, apenas, não perder de vista que é o pesquisador quem define os objetivos da pesquisa, quem escolhe o método de investigação, quem realiza entrevistas, elabora o roteiro, registra respostas, transcreve, arquiva, interpreta e escreve e assina o texto final (velHo, 1986). Seu ponto de partida será sempre aquilo que o informante lhe diz, pois isso é sua matéria-prima. Porém, produtos da cultura, sejam industriais, acadêmicos ou artísticos, não são apresentados enquanto matérias-primas - para que sejam produto, tem que haver trabalho, investimento, modificações, supressões, manufatura. Portanto, não cabe supor que relatórios de pesquisa ou teses de doutorado devam funcionar tão somente como "caixas de ressonância" de falas alheias, cadeias de transmissão de idéias e reivindicações de grupos "sem voz" no meio acadêmico.

Outra idéia a meu ver equivocada, que freqüentemente atravessa o trabalho com entrevistas, é a de que tudo que é dito pelo entrevistado tem que ser objeto de análise; de que tudo que foi dito é importante só por ter sido dito. Não é exatamente assim. Entrevistas bem realizadas, com um número adequado de informantes, produzem uma imensa "massa" de informações

${ }^{2}$ Em um seminário sobre interculturalismo, identidade e diferenças ouvi um pesquisador muito competente e sério relatar o trabalho experimental que vinha realizando com uma comunidade quilombola na Bahia. Nesse trabalho a comunidade "pesquisada" havia participado de todas as etapas da pesquisa (elaboração de projeto, construção e análise do material empírico, criação de categorias, revisão bibliográfica, escritura de relatórios, artigos etc). Esse é um procedimento radical, que tem como pressuposto o compartilhamento da produção do conhecimento científico. Não disponho de dados para avaliar a qualidade desse trabalho específico (nem acho que tenha o direito de fazê-lo), apenas faço aqui o registro de que procedimentos assim existem e dão à pesquisa um caráter totalmente distinto do que ela tem nas "circunstâncias-padrão". 
que não pode nem deve ser tomada como um todo. Do conjunto do material generosamente oferecido a nós pelos nossos informantes, só nos interessa aquilo que está diretamente relacionado aos objetivos da nossa pesquisa (QUEIROZ, 1988) e é isso que deverá ser objeto de leitura.

Por outro lado, muito do que nos é dito é profundamente subjetivo, pois trata-se do modo como aquele sujeito observa, vivencia e analisa seu tempo histórico, seu momento, seu meio social etc.; é sempre um, entre muitos pontos de vista possíveis. Assim, tomar depoimentos como fonte de investigação implica extrair daquilo que é subjetivo e pessoal neles o que nos permite pensar a dimensão coletiva, isto é, que nos permite compreender a lógica das relações que se estabelecem (estabeleceram) no interior dos grupos sociais dos quais o entrevistado participa (participou), em um determinado tempo e lugar.

A garantia de confiabilidade das pesquisas passa, necessariamente, pela explicitação das relações existentes entre os procedimentos adotados na coleta de material empírico, a literatura científica, o objeto de pesquisa e os resultados obtidos a partir dessas relações (LEONARDOS, BRITO, 2001). Segundo Ana Cristina LEONARDOS e Ângela Xavier de BRITO, "toda escolha de um equipamento conceitual e operacional a ser adotado em um estudo ocorre em razão de uma interação entre o objeto a conhecer e a personalidade do pesquisador (...). Daí a importância de explicitar-se e justificar as opções metodológicas contextualmente, mediante descrição dos procedimentos priorizados e das formas pelas quais as informações foram obtidas e sistematizadas" (2001, p. 27).

Penso que, no caso de pesquisas que fazem uso de entrevistas, é necessário explicitar sempre: a) as razões pelas quais optou-se pelo uso daquele instrumento; b) os critérios utilizados para a seleção dos entrevistados; c) número de informantes; d) quadro descritivo dos informantes - sexo, idade, profissão, escolaridade, posição social no universo investigado etc. e) como se deram as situações de contato (como os entrevistados foram convidados a dar seu depoimento, em que circunstâncias as entrevistas foram realizadas, como transcorreram etc.); f) roteiro da entrevista (de preferência em anexo) e, g) procedimentos de análise (anexando, no final do texto ou relatório, cópia de uma das transcrições - desde que não haja necessidade de preservar a identidade do informante). ${ }^{3}$

${ }^{3}$ Uma das maneiras de garantir rigor e confiabilidade na realização de entrevistas é recorrer ao inter-rater reliability, proposto à comunidade acadêmica como procedimento regular, em 1997, por pesquisadores estadonidenses (ARMSTRONG, 1997). Trata-se da troca de entrevistas transcritas, entre pesquisadores de diferentes campos de pesquisa, para análise da qualidade das mesmas, ao longo da realização do trabalho de campo. Esse procedimento pode ser muito produtivo se for adotado por pesquisadores (ou estudantes de Pós-Graduação) de diferentes instituições de pesquisa, sob a coordenação do mais experiente dentre eles. 
Uma crença relativamente comum entre os que fazem uso de entrevistas em suas investigações é a de que a empatia com o entrevistado é essencial para a realização de uma boa entrevista. Mas não é necessariamente assim. No que se refere à pesquisa científica, "a empatia não é fundamento da comunicação com o outro" (ROMANELLI, op. cit.: 129). Para ver o mundo pelo ponto de vista do entrevistado, para compreender sua lógica e produzir conhecimento sobre sua existência, não é preciso identificar-se com ele ou com as posições que ele defende; é fundamental "elaborar, no plano teórico, modos de expressão que traduzam seu sistema simbólico" (idem).

Muitas vezes os pesquisadores sentem um certo desconforto quando realizam entrevistas, pois imaginam-se retirando algo muito precioso do outro sem lhe dar nada em troca. Não há porque nos sentirmos assim; entrevista é sempre troca, afirma ROMANELLI no texto citado; ao mesmo tempo em que coleta informações, o pesquisador oferece ao seu interlocutor a oportunidade de refletir sobre si mesmo, de refazer seu percurso biográfico, pensar sobre sua cultura, seus valores, a história e as marcas que constituem o grupo social ao qual pertence, as tradições de sua comunidade e de seu povo. Quando realizamos uma entrevista, atuamos como mediadores para o sujeito apreender sua própria situação de outro ângulo, conduzimos o outro a se voltar sobre si próprio; incitamo-lo a procurar relações e a organizá-las. Fornecendo-nos matéria-prima para nossas pesquisas, nossos informantes estão também refletindo sobre suas próprias vidas e dando um novo sentido a elas. Avaliando seu meio social, ele estará se auto-avaliando, se auto-afirmando perante sua comunidade e perante a sociedade, legitimando-se como interlocutor e refletindo sobre questões em torno das quais talvez não se detivesse em outras circunstâncias.

\section{Transcrição e análise de entrevistas}

Há alguns procedimentos importantes a serem adotados na preparação de entrevistas para a análise. O primeiro deles diz respeito à transcrição: entrevistas devem ser transcritas, logo depois de encerradas, de preferência por quem as realiza. Depois de transcrita, a entrevista deve passar pela chamada conferência de fidedignidade: ouvir a gravação tendo o texto transcrito em mãos, acompanhando e conferindo cada frase, mudanças de entonação, interjeições, interrupções etc. Transcrever e ler cada entrevista realizada, antes de 
partir para a seguinte ajuda a corrigir erros, a evitar respostas induzidas e a reavaliar os rumos da investigação (ALBERTI, 1990).

Entrevistas podem e devem ser editadas. Exceto quando se pretende fazer análise de discurso, frases excessivamente coloquiais, interjeições, repetições, falas incompletas, vícios de linguagem, cacoetes, erros gramaticais etc. devem ser corrigidos na transcrição editada. É importante, porém, manter uma versão original e uma versão editada de todas as transcrições. Da versão editada, devem ser retiradas também as respostas obtidas por meio de perguntas capciosas, ambíguas, tendenciosas ou que tenham levado o informante a confirmar ou negar afirmações feitas pelo pesquisador.

Uma maneira de analisar é fragmentar o todo e reorganizar os fragmentos a partir de novos pressupostos. Trata-se, nesse caso, de segmentar a fala dos entrevistados em unidades de significação - o mínimo de texto necessário à compreensão do significado por parte de quem analisa - e iniciar um procedimento minucioso de interpretação de cada uma dessas unidades, articulando-as entre si, tendo por objetivo a formulação de hipóteses explicativas do problema ou do universo estudado. Nessa perspectiva, a interpretação exige que as unidades de significação (oriundas da fragmentação das entrevistas) sejam articuladas umas às outras a partir de categorias de análise: lembranças de escola, por exemplo, pode ser uma categoria de análise, assim como formação inicial, socialização profissional, gosto etc. Nesse caso, todas as unidades de texto retiradas das falas dos informantes que tiverem relação, por exemplo, com o indexador "lembranças de escola", deverão ser agrupadas sob esse indexador. ${ }^{4}$

As categorias de análise podem ser eleitas pelo pesquisador antes da realização das entrevistas (integrando, portanto, os objetivos das mesmas), a partir de referências teórico/conceituais (como "geração", "leitura", "protagonismo", "socialização profissional" etc.) ou de um conhecimento prévio do campo empírico ("tendências", por exemplo, é uma categoria importante a ser adotada por um pesquisador que se proponha a estudar o movimento estudantil brasileiro). Podem também emergir no momento da análise, pela identificação por parte do pesquisador de conteúdos recorrentes no discurso de seus entrevistados ("pedaço", "desbunde", "rato de cinema" etc. são tipos de categorias que emergem no trabalho de campo). A análise final

${ }^{4}$ Os procedimentos de análise apresentados aqui compõem a estrutura operacional dos bons softwares para análise de dados qualitativos que, na minha opinião, facilitam em muito o trabalho analítico e auxiliam na garantia da qualidade do trabalho. 
das entrevistas consistirá em dar sentido ao conteúdo do mosaico de categorias ou indexadores no interior dos quais estarão agrupadas as unidades de significação, tendo como referência os objetivos da pesquisa e o contexto em que os depoimentos foram colhidos.

No que diz respeito à interpretação de entrevistas abertas ou semiestruturadas, análises temáticas podem ser um recurso que "encurta o caminho" do pesquisador, sobretudo quando se trata de pesquisadores iniciantes. Nesse caso, pode-se tomar o conjunto de informações recolhidas junto aos entrevistados e organizá-las, primeiramente, em três ou quatro grandes eixos temáticos, articulados aos objetivos centrais da pesquisa. Assim, por exemplo, numa pesquisa que tenha por objetivo analisar o posicionamento de professores de um determinado curso universitário frente ao ingresso de estudantes por meio do sistema de cotas, poder-se-ia ter como eixos temáticos iniciais para análise das entrevistas concedidas pelos professores: 1) visão de universidade; 2) posição frente ao sistema de cotas; 3) opinião sobre os cotistas; 4) impacto provocado no curso pelo ingresso de estudantes cotistas.

A partir daí, proceder-se-ia à construção de subeixos temáticos, cada vez mais precisos e específicos em relação ao objeto de pesquisa, em torno dos quais seriam organizadas as falas dos entrevistados recolhidas a partir da fragmentação dos discursos. Retomando o exemplo acima, teríamos, por exemplo, dentro do eixo 1, os subeixos: relação entre universidade e sociedade; universidade e mobilidade social; universidade e formação de elite; igualdade $\mathrm{x}$ pluralismo, e assim por diante. Ao final, o cruzamento das falas dos entrevistados seria realizado pela articulação dos conteúdos dos diferentes eixos e subeixos temáticos, conduzida pelo pesquisador a partir de seus pressupostos.

Portanto, os dados de uma pesquisa desse tipo serão sempre resultado da ordenação do material empírico coletado/construído no trabalho de campo, que passa pela interpretação dos fragmentos dos discursos dos entrevistados, organizados em torno de categorias ou eixos temáticos, e do cruzamento desse material com as referências teórico/conceituais que orientam o olhar desse pesquisador. Isso implica a construção de um novo texto, que articula as falas dos diferentes informantes, promovendo uma espécie de "diálogo artificial" entre elas, aproximando respostas semelhantes, complementares ou divergentes de modo a identificar recorrências, concordâncias, contradições, divergências etc. Esse procedimento ajuda a compreender a natureza e a lógica das relações estabelecidas naquele contexto e o modo como os diferentes interlocutores percebem o problema com o qual ele está lidando.

Cabe ao pesquisador atribuir sentido àquele mosaico, tendo como referência seus pressupostos teóricos, sua filiação acadêmica, seus objetivos de 
pesquisa etc. Cabe a ele, também, nesse procedimento, "desconfiar" dos seus interlocutores, como sugere MAGNANI (1986). Muitas vezes o entrevistado "encena um personagem" que, intuitivamente, percebe que o pesquisador deseja que ele seja ou diz o que acredita que o pesquisador gostaria de ouvir. Assim, nem tudo o que o informante diz deve ser tomado como "verdade"; trata-se da verdade dele, do ponto de vista dele, que precisa ser confrontado com outros olhares e com a prática observada no campo pelo pesquisador.

Os resultados obtidos a partir dessa "manufatura" das informações coletadas devem ser apresentados aos informantes, para verificar se a leitura feita e se as hipóteses formuladas a partir dela têm fundamento para aqueles que vivenciam mais diretamente as circunstâncias investigadas: uma espécie de "devolução", que ajuda a evitar distorções. Os resultados deverão ser cruzados, posteriormente, com registros de observações de campo (se houver), dados quantitativos e/ou informações adicionais acerca daquela temática ou daquela população (estudos precedentes, levantamentos estatísticos, matérias jornalísticas, documentos históricos, artigos, imagens, textos literários etc.), de modo a possibilitar uma visão o mais ampla possível do universo que está sendo investigado.

Ao longo de todo o processo de análise, o material empírico estará sendo lido/visto/interpretado à luz da literatura científica de referência para o pesquisador, que produz teoria articulada ao conjunto de produções científicas com o qual se identifica. Vale lembrar, entretanto, que a fala do entrevistado tem valor nela mesma quando tomada como fonte de conhecimento e não pode ser utilizada como mera ilustração das teorias explicativas. Se recolhido e analisado de forma correta, o material fornecido por nossos informantes tem concretude, densidade e legitimidade suficientes para, se for o caso, fornecer subsídio e base para questionarmos nossos pressupostos e mesmo concepções teóricas estabelecidas e consolidadas.

Os depoimentos coletados também podem, em muitos casos, refutar as idéias que o pesquisador tinha a respeito do problema antes de iniciar a pesquisa de campo. Por tudo isso, o fundamental é estar aberto às surpresas, ao imprevisível e ao imponderável que emergem do trabalho de campo, mesmo que isso nos obrigue a rever nossos conceitos e a refazer o caminho trilhado. Dar espaço para a emergência do novo é o que justifica a realização de pesquisas empíricas e o que as torna tão fascinantes e tão necessárias ao contexto, um tanto enrijecido e repetitivo, em que vêm sendo realizados boa parte de nossos estudos. 


\section{Considerações finais}

Tentei dar a este texto um tom informal (às vezes didático) porque tinha como objetivo responder à demanda de muitos estudantes de Pós-Graduação que nos procuram pedindo indicações sobre como proceder na realização e análise de entrevistas. Não pretendi dar uma receita, apenas orientações, que julgo facilitadoras, acerca de como realizar esse trabalho, estando atentos, permanentemente, ao rigor e à confiabilidade que ele precisa ter. Tenho certeza de que outros pesquisadores desenvolvem seu trabalho de maneira distinta da que apresentei aqui; vale reafirmar, portanto, que não se trata de um modelo ideal, mas de uma dentre muitas possibilidades de lidar com entrevistas em uma investigação científica no campo das Ciências Sociais e Humanas.

\section{REFERÊNCIAS}

ALBERTI, V. História oral: a experiência do CPDOC. Rio de Janeiro: Fundação Getúlio Vargas, 1990.

ARMSTRONG, D. et al. The place of inter-rater reliability in qualitative research: an empirical study. Sociology, v. 31, n. 3, p. 597-606, ago. 1997.

BRANDÃO, Z. Entre questionários e entrevistas. In: NOGUERIA, M. A.; ROMANELLI, G.; ZAGO, N. (Org.). Família e escola. Rio de Janeiro: Vozes, 2000. p. 171-183.

BRITO, A. X. de; LEONARDOS; A. C. A identidade das pesquisas qualitativas: construção de um quadro analítico. Cadernos de Pesquisa, Campinas, n. 113, p. 7-38, jul. 2001.

DUARTE, R. Pesquisa qualitativa: reflexões sobre trabalho de campo. Cadernos de Pesquisa, Campinas, n. 115, p. 139-154, jul. 2001.

ECO, U. Interpretação e superinterpretação. São Paulo: Martins Fontes, 1993.

MAGNANI, J. G. C. Discurso e representação, ou de como os Baloma de Kiriwina podem reencarnar-se nas atuais pesquisas. In: CARDOSO, R. (Org.). A aventura antropológica: teoria e pesquisa. Rio de Janeiro: Paz e Terra, 1986. p. 127-140.

QUEIROZ, M. I. P. de. Relatos orais: do indizivel ao dizível. In: VON SIMSON, O. (Org.). Experimentos com histórias de vida (Itália-Brasil). São Paulo: Vértice; Editora Revista dos Tribunais, 1988. Enciclopédia Aberta de Ciências Sociais, v. 5. 
ROMANELLI, G. A entrevista antropológica: troca e alteridade. Revista do Programa de Pós-Graduação em Psicologia da Faculdade de Filosofia, Ciências e Letras de Ribeirão Preto, Ribeirão Preto, p. 119-133, 1998.

VELHO, G. Subjetividade e sociedade: uma experiência de geração. Rio de Janeiro: Zahar, 1986.

Texto recebido em 16 de maio 2004 Texto aprovado em 15 de out. 2004 